\title{
THE INFLUENCE OF THE TYPE OF A BEVERAGE ON ITS PACKAGING SHAPE
}

\author{
Gordana Delić (D), Gojko Vladić (D), Bojan Banjanin (D), Jelena Vasić (iD \\ University of Novi Sad, Faculty of Technical Sciences, \\ Department of Graphic Engineering and Design, Novi Sad, Serbia
}

\begin{abstract}
A lot of research today implies that packaging attributes have an essential role in attracting consumer attention, creating expectations and influencing product choice. Many studies have documented that people match a variety of tastes, aromas, and flavours to other sensory features, such as shapes and colours. This study investigates the influence of the type of a beverage on its packaging shape. The study is designed to discover what packaging materials, the shape of packaging body and the type of packaging opening consumers prefer for each beverage: milk (chocolate milk, milkshake), soda, juice, yoghurt, fruit yoghurt, water and ice coffee. The investigation was conducted through a survey where participants were asked to choose a packaging shape from a variety of presented shapes. The stimuli that were used were grayscale photographs of packaging without any graphic design applied. These packaging differed not only in shape but also in materials from which they were made and the type of opening system. The result implies that participants that consumed a certain type of drink on regular basis were more open for new different atypical packaging shapes. On the other hand, for products that they consumed less, they preferred a packaging that was most commonly presented and placed on the market where they live. Also, these results support the view of many researchers that delicate and subtle flavours were best presented in packaging with rounded and curvy shapes, while sour and intense flavours are best presented with angular shapes. Characteristic that turned out to be very important was the shape of the packaging body but in terms of ergonomics and ease of use. It was found that there is a positive correlation between aesthetic features and ergonomic features of the packaging. These findings are relevant to those researchers interested in tastevision correspondences, it should contribute to product communication, and it can be used as a base for future research focused on packaging shape and ergonomics.
\end{abstract}

Key words: beverage, drink, packaging, shape, ergonomics

\section{INTRODUCTION}

A growing body of empirical research suggests that packaging has replaced the role of salespersons in the communication with consumers at the point of purchase. Today, most consumers postpone their purchase decisions to the moment when they find themselves in the store, so the first impression between the consumer and a product, or to be more precise, the packaging of the product has become relevant. However, communication through packaging has become more challenging, since the number of products that are offered is rapidly increasing. In such an environment cluttered with products, purchase decisions are often not based on a systematic and critical evaluation of product features, but rather on heuristic and fast processing of packaging cues. Marketers respond to this development by using various visual techniques to increase the consumer's attention, such as the use of original materials, shapes, and colours in their packaging (Ooijen et al, 2016).

The traditional functions of packaging for beverage and food are to protect the products from degradation processes (primarily produced by environmental factors, such as oxygen, light and moisture), to contain the product, and to provide consumers with ingredient and nutritional information. The packaging here acts as a barrier between the food product and the outside environment while avoiding the migration of harmful substances from the packaging to the food. Materials that have traditionally been used in beverage/food packaging include glass, metals (aluminium, foils and laminates, tinplate, and tin-free steel), paper and paperboards, and plastics. The right selection of the packaging material plays a vital role in maintaining product quality and freshness during distribution and storage. Packaging for beverage often combines several materials to exploit each material's functional or aesthetic properties. New advances in this field include the development of multilayer systems, new approaches based on active or intelligent packaging, or materials with lower environmental impacts as bio-based polymers. The use of plastics in beverage packaging has continued to increase due to the low cost of materials and functional advantages (such as thermosealability, microwavability, optical properties, and unlimited sizes and shapes) over traditional materials such as glass and tinplate (Ramos et al, 2015). Packaging openability and usability is an area that has been explored by ergonomics in its various aspects: biomechanical, anthropometric, and 
also the cognitive, which involves perception and comprehension of the information provided. The packaging openability and usability is important especially for products such as beverages that are meant to be used in "to go" situations. In this situations, opening that requires the use of scissors wouldn't be the best way to go, but the opening system that includes a simple twist motion such as screw thread caps, or packaging that includes a straw hole (and a straw) would be easier to use (Bonfim et al, 2015). Over the past three decades, a lot of research has highlighted how beverage and food packaging can inform, tempt, and bias the consumer, both at the point of sale, as well as during consumption. Ongoing investigations suggest that even relatively minor adjustments to the visual design of the packaging, such as to the shapes, colours, orientations, and positions of design elements, can significantly impact consumer's product evaluations and purchase intent either positively or negatively (Simmonds et al, 2018; Steenis, 2017; Vladić et al, 2015). With improvements in packaging technology come new opportunities for packaging design. One such trend is the ability to introduce transparency into a wide range of product packaging. Results suggested that transparent packaging increased willingness to purchase, expected freshness, and expected quality, as compared to packaging that used food imagery instead. Also, participants assumed the products to be tastier, to be more innovative etc. (Westerman et al, 2013).

Ooijen et al. (2016) investigated the influence of atypicality of packaging on product quality perception. The researchers found support for the hypothesis that atypical packaging design enhances the processing of product information, and improves the recall of product claims presented on the product. They found that the persuasiveness of weak and strong product claims on the packaging was affected by whether the packaging design was typical or atypical. When packaging was atypical, strong claims resulted in a higher quality judgment, but weak claims resulted in a lower willingness to pay - compared to when packaging was typical. Therefore, atypical packaging may not always be beneficial for product evaluation (Ooijen et al, 2016).

Most drink and food products come in packaging of a particular shape or form, whose attributes prime various concepts in the mind of the consumer. A growing body of empirical research now demonstrates that people associate different basic tastes and taste words with specific packaging shapes. While it may be evident that semantic knowledge concerning products, based on the packaging and design elements (e.g., typeface, logo, images), can guide the taste expectations that consumers generate about a given product, many research work has been done to demonstrate that this happens even with unfamiliar stimuli. Specifically, shape features (e.g., straight vs curvy, or symmetrical vs asymmetrical) have been shown to influence the taste that people naturally associate with a given shape. It was found that people match tastes and shape features in a manner that is significantly non-random and both packages and their respective shape-related features can convey information about the likely taste of a product (Velasco, 2016; Becker et al, 2011; Valesco et al, 2014; Machiels et al, 2016; Husić-Mehmedović et al, 2017). In a similar field, research was done to investigate whether shape-taste correspondences would influence consumers' expectations concerning coffee. Amongst other findings, the results revealed that the coffee was expected to be more aromatic from narrower diameter mugs, the coffee associated with shorter mugs was expected to be both bitterer and more intense, and the coffee was expected to be sweeter from wider diameter mugs (Doorn et al, 2017).

There are also researches focused on the influence of the packaging colour on packaging perception. In food packaging, light and pale colours are often used to highlight product healthiness. What has been found is that positive health cues may also convey another crucial information about the taste of the product which with pale colours often gets a negative connotation.

As it has been presented in previous text, a lot of research today implies that packaging attributes have an important role in attracting consumer attention, creating expectations and influencing product choice. Many studies have documented that people match a variety of tastes, aromas, and flavours to other sensory features, such as shapes and colours. This study investigates the influence of the type of a beverage on its packaging shape, materials of the packaging, and the type of packaging opening system. The investigation was done through a survey where the participants were asked to define the packaging with the best aesthetic and ergonomics features for a certain type of a beverage. Investigated beverages were: milk (chocolate milk, milkshake), soda, juice, yoghurt, fruit yoghurt, water and ice coffee.

\section{METHODS}

The research was conducted through a survey completed by 30 participants. The age range of participants was 21-22. Demographic data of participants such as gender was also collected. In the first part of the survey, participants were asked to define which beverage they usually consume at lunch break at college 
or work and to define the most important characteristics they look for while buying that product. The next series of questions of the survey was divided into seven parts that included the same questions, but in each part the questions were focused on a different kind of beverage. These were: milk (chocolate milk, milkshake), soda drink, juice, yoghurt, fruit yoghurt, water, and ice coffee. For each type of beverage, participants were asked to choose the most suitable packaging from 6 different types of presented packaging. By selecting a type of packaging, they were asked to define the reasons for choosing that packaging and then they were broth to a series of questions related to the selected type of packaging. Here, the chosen type of packaging was divided into several version of that packaging. The versions varied mostly in shape of the body or in type of an opening system. The participants had the task to choose the version with the best aesthetics, the packaging with the most comfortable shape, the packaging with the best opening and the packaging with the best closing system. As mention, these series of question repeated for every type of beverage. Since all the packaging were evaluated as products that are used outside of the home, at college or work, all the questions and stimuli were formed with a focus on that. The participants could take as much time as they needed to complete the survey.

\subsection{Stimuli used in the research}

The stimuli that were used in the survey were grayscale photographs of packaging without any graphic design applied. These packaging differed not only in shape but also in materials from which they were made and the type of opening system. Stimuli that were used can be divided into 6 types of packaging that differ in a base material or basic shape from which they were made. Each type is marked with a letter: group A: plastic cup-shaped packaging; group B: plastic bottle; group C: glass bottle; group D: bag-shaped packaging; group E: metal can packaging; group F: packaging made of plastic-coated carton known as tetra pak (in upcoming text referred to as tetra pak). Also, within one group there were more variations of that type of a packaging in order to divide them by a body shape, opening or closing system. Variations within one group are marked with a number. All packaging had about the same volume, so the size of the packaging was not an influencing factor. Based on this division there were 36 different packaging. All the packaging used as stimuli in this research are shown in Figure 1. The layout of one question from the survey is shown in Figure 2.

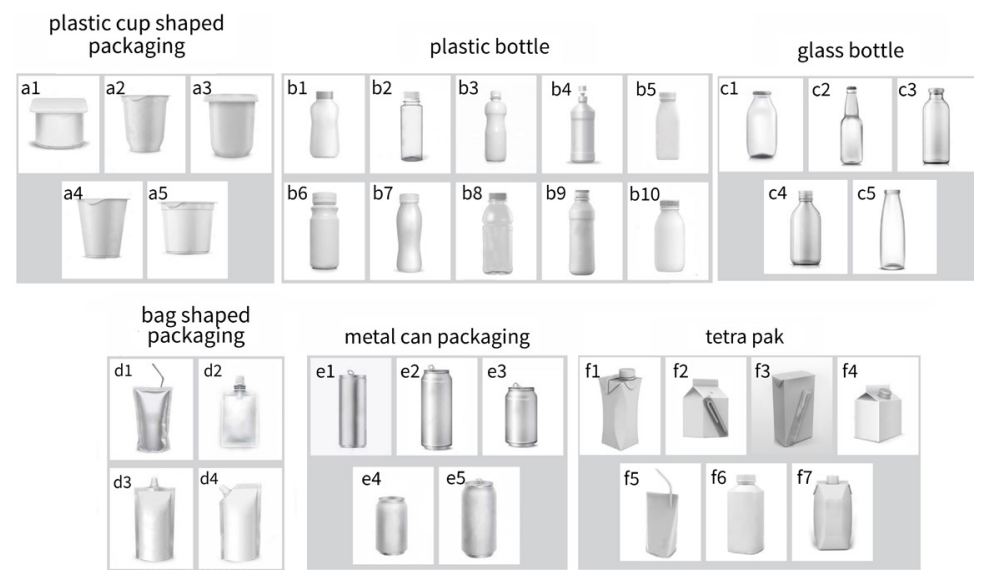

Figure 1. Packaging that were used as stimuli in this research

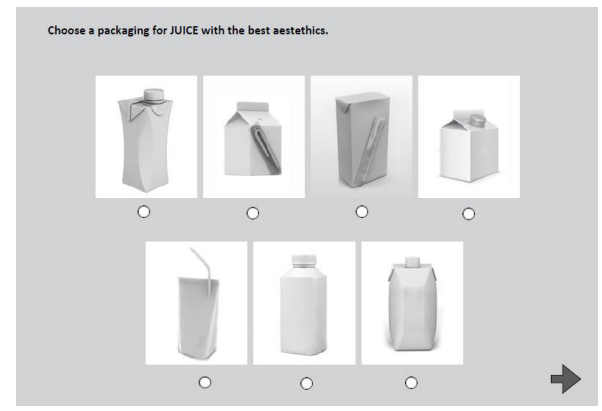

Figure 2: Example of one question from the survey 


\section{RESULTS AND DISCUSSION}

The responses from 30 participants were collected and presented graphically. At the question: "What do you usually drink during lunch break at college/work?" the most frequent answer was water (70\%), as shown in Figure 3. At the question: "What is most important to you when choosing a beverage?" most frequent answer was the quality of the product inside it and portability and convenience to carry it in a purse/bag. Other answers can be seen in Figure 4.

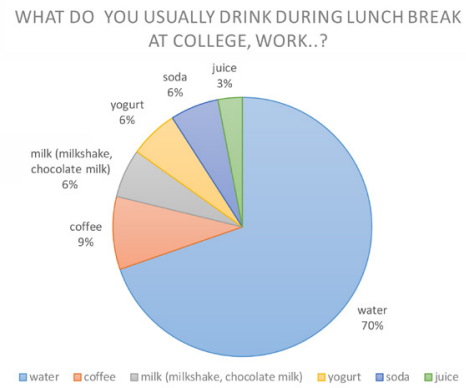

Figure 3: The most consumed beverages by participants

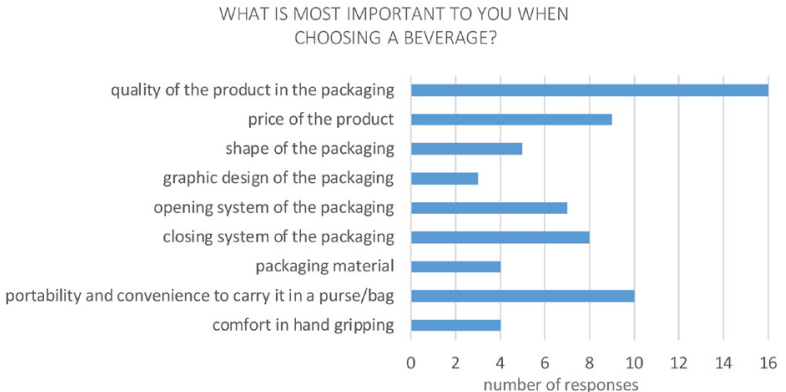

Figure 4: The most important features of the product considered while purchasing rated by participants

\subsection{Aesthetic and ergonomic features of the packaging}

Since the purpose of this research was to investigate the type of a beverage as an influencing factor on choosing the packaging shape, the collected responses given by participants of the packaging with the best aesthetic features and most comfortable shape were analysed within one type of a beverage.

Milk (milkshake, chocolate milk) - Collected responses of packaging for milk (milkshake, chocolate milk) with the best aesthetic features and the most comfortable shape are presented in Figure 5. As it can be seen in Figure 5, for milk (milkshake, chocolate milk) participants prefer plastic bottles, glass bottles and tetra pak packaging. From those, based on the number of responses, packaging with the best aesthetic features were b2, b7, f1 and f6 (Figure 5a), and the most comfortable shape of the packaging had the packaging b7 and f1 (Figure 5b). Participants preferred tetra pack mainly because it is practical for use and portable, it has a good opening system and the packaging material is light. As the best feature of plastic packaging, they emphasised a good closing system.

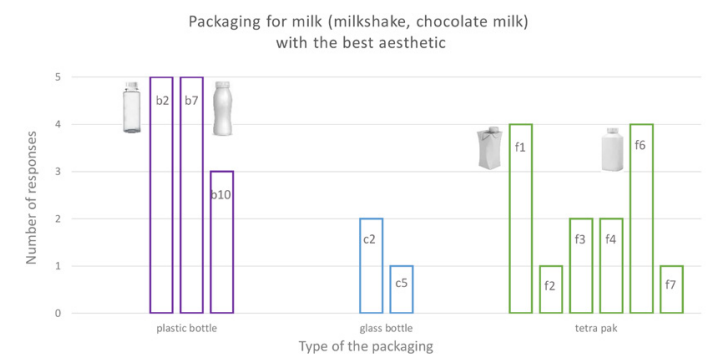

a)

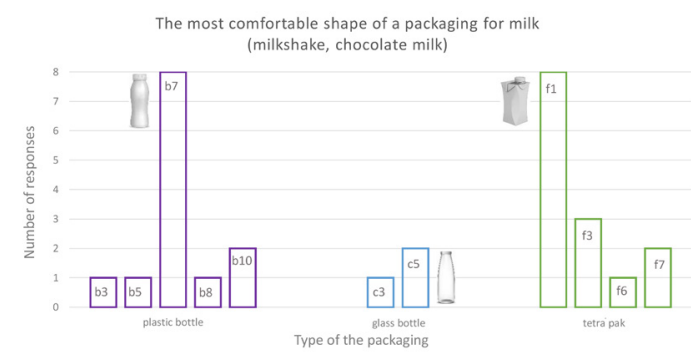

b)

Figure 5: Packaging for milk (milkshake, chocolate milk) with the best aesthetic (a) and the most comfortable shape (b) based on participants' ratings

Soda drink - Collected responses of packaging for soda drink with the best aesthetic features and the most comfortable shape are presented in Figure 6. As it can be seen, for soda drink participants prefer plastic bottles, glass bottles and metal can packaging. From those, based on the number of responses, packaging with the best aesthetic features were b2, b9, e1 and e2 (Figure 6a), and the most comfortable shape of the packaging had the packaging b3, e2 and e3 (Figure 6b). Participants preferred plastic bottles mainly because they thought it is standard packaging for that product (soda), it is practical for use and portable, it has a good closing system and the packaging material is light. The most common reason for choosing a metal can packaging was the standard shape of the packaging on which they are used to, and they liked the aesthetic of that type of the packaging. 


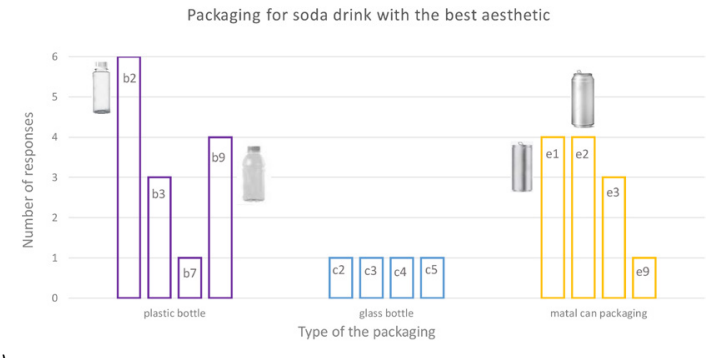

a)

b)

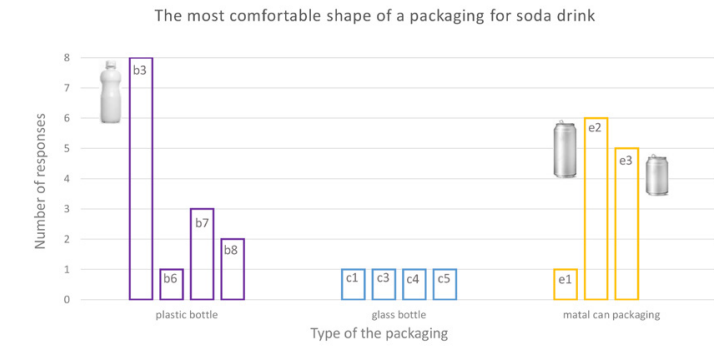

Figure 6: Packaging soda drink with the best aesthetic (a) and the most comfortable shape (b) based on participants' ratings

Juice - Collected responses of packaging for juice with the best aesthetic features and the most comfortable shape are presented in Figure 7. As it can be seen for juice, participants prefer plastic bottles, glass bottles, bag-shaped packaging, metal can packaging and tetra pak packaging. From those, based on the number of responses, packaging with the best aesthetic features were b2, c5 and d4 (Figure 7a), and the most comfortable shape of the packaging had the packaging b3, b7 and d4 (Figure 7b). Participant preferred plastic packaging because it has a good closing system, it is practical for use and portable, it is comfortable for hand gripping, it has a stable stand (it stays steady on the table) and because the packaging material is light. The second most common choice was bag-shaped packaging, mostly because they thought it is standard packaging for that type of a beverage and the material of the packaging is light.
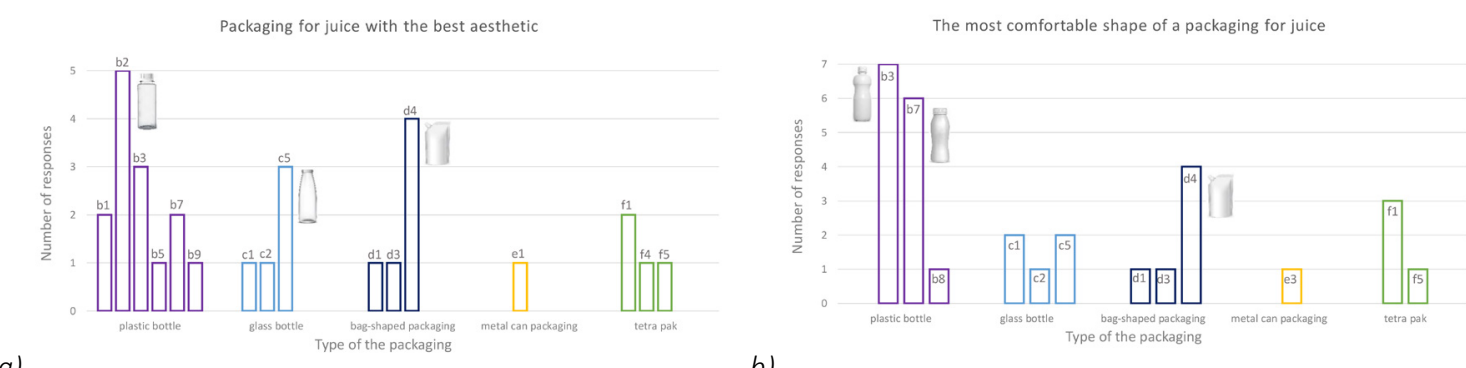

b)

Figure 7: Packaging for juice with the best aesthetic (a) and the most comfortable shape (b) based on participants' ratings

Yoghurt - Collected responses of packaging for yoghurt with the best aesthetic features and the most comfortable shape are presented in Figure 8. As it can be seen for yoghurt, participants prefer plastic bottles, tetra pak packaging, plastic cup-shaped packaging and glass bottles. From those, based on the number of responses, packaging with the best aesthetic features were b7 and b5 (Figure 8a), and the most comfortable shape of the packaging had the packaging b7 (Figure 8b). Participants preferred plastic packaging because it has a good opening and closing system, it is practical for use and portable and it is comfortable for hand gripping.

a)

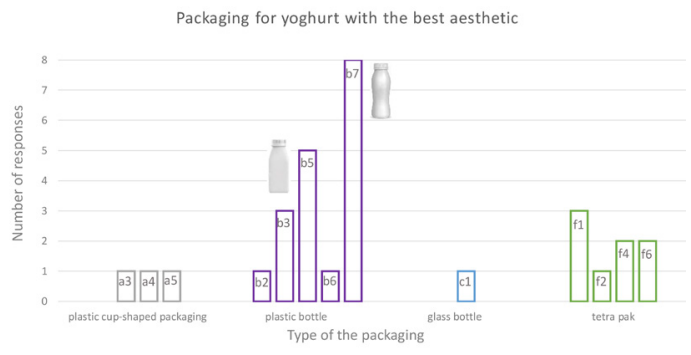

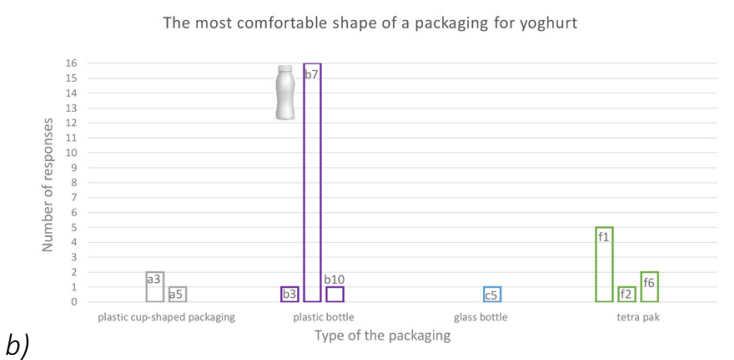

Figure 8: Packaging for yoghurt with the best aesthetic (a) and the most comfortable shape (b) based on participants' ratings 
Fruit yoghurt - Collected responses of packaging for fruit yoghurt with the best aesthetic features and the most comfortable shape are presented in Figure 9. As it can be seen for fruit yoghurt, participants prefer plastic bottles, plastic cup-shaped packaging and tetra pak packaging. From those, based on the number of responses, packaging with the best aesthetic features was b7 (Figure 9a), and the most comfortable shape of the packaging had the packaging b7 (Figure 9b). Participant preferred plastic packaging because they think it is a standard packaging for that type of a beverage, it has a good opening and closing system, it is practical for use and portable, it is comfortable for hand gripping and it has a stable stand (it stays steady on the table).
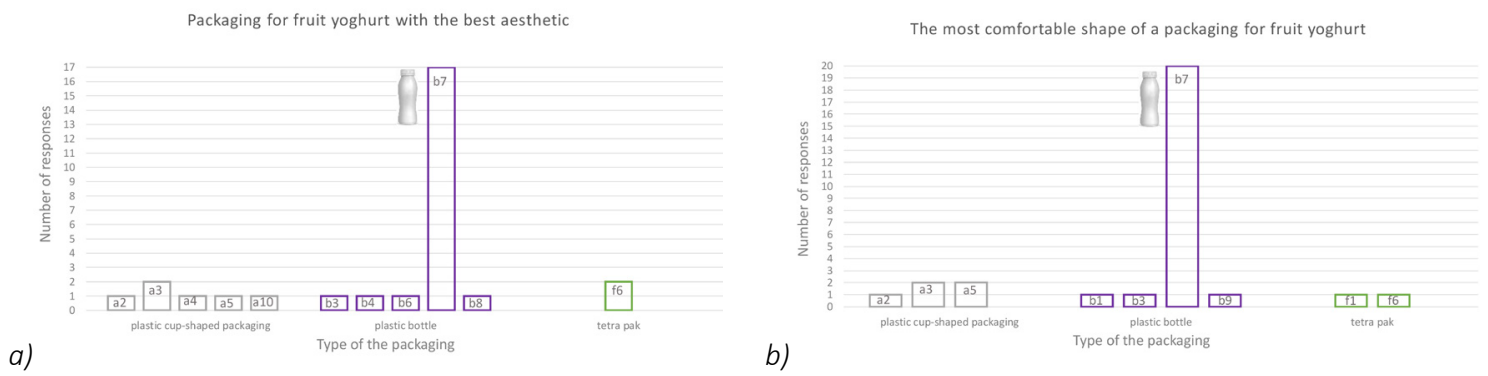

Figure 9: Packaging for fruit yoghurt with the best aesthetic (a) and the most comfortable shape (b) based on participants' ratings

Water - Collected responses of packaging for water with the best aesthetic features and the most comfortable shape are presented in Figure 10.

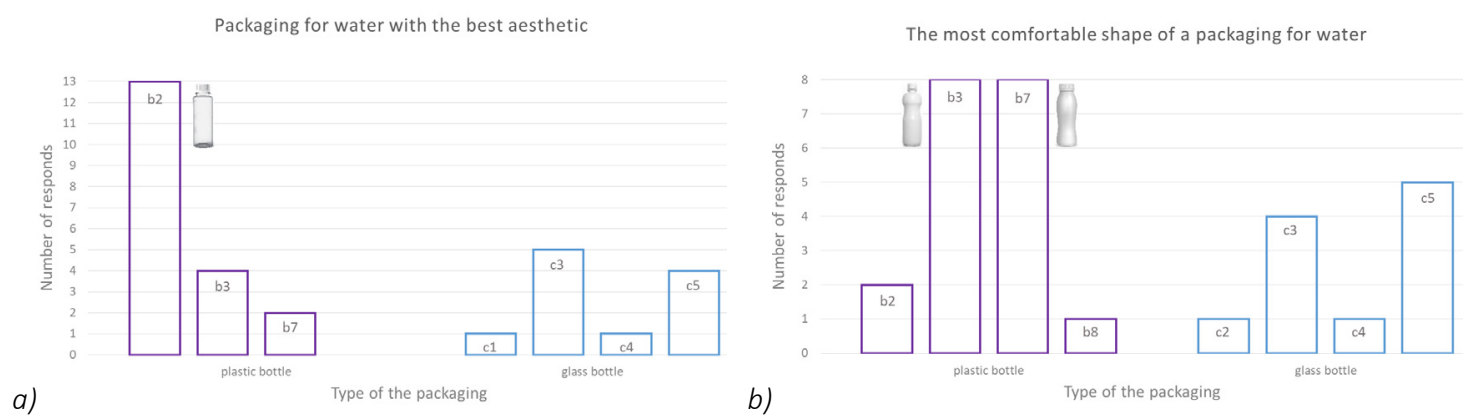

Figure 10: Packaging for water with the best aesthetic (a) and the most comfortable shape (b) based on participants' ratings

As it can be seen in Figure 10, participants prefer plastic bottles and glass bottles for water packaging. From those, based on the number of responses, packaging with the best aesthetic features was b2 (Figure 10a), and the most comfortable shape of the packaging had the packaging b3 and b7 (Figure 10b). Participant preferred plastic packaging because they thought it is a standard packaging for that type of a drink, it has a good opening and closing system, it is practical for use and portable and it is comfortable for hand gripping. The second most common choice was glass bottles, mostly because they are good for the environment, and their aesthetic features.

Ice coffee - Collected responses of packaging for ice coffee with the best aesthetic features and the most comfortable shape are presented in Figure 11. As it can be seen for ice coffee, participants prefer plastic cup-shaped packaging, plastic bottles, glass bottles, metal can packaging and tetra pak packaging. From those, based on the number of responses, packaging with the best aesthetic features was a4, b7 and e1 (Figure 11a), and the most comfortable shape of the packaging had the packaging a2 and b7 (Figure 11b). Participant preferred plastic cup-shaped packaging because it was made from a light material and it had a stable stand (it stays steady on the table). The second most common choice was plastic bottles because they have a good opening and closing system, it is practical for use and its portable, it is comfortable for hand gripping and it has a stable stand. The third most common choice was a metal can packaging mostly because participants preferred their aesthetic features. 

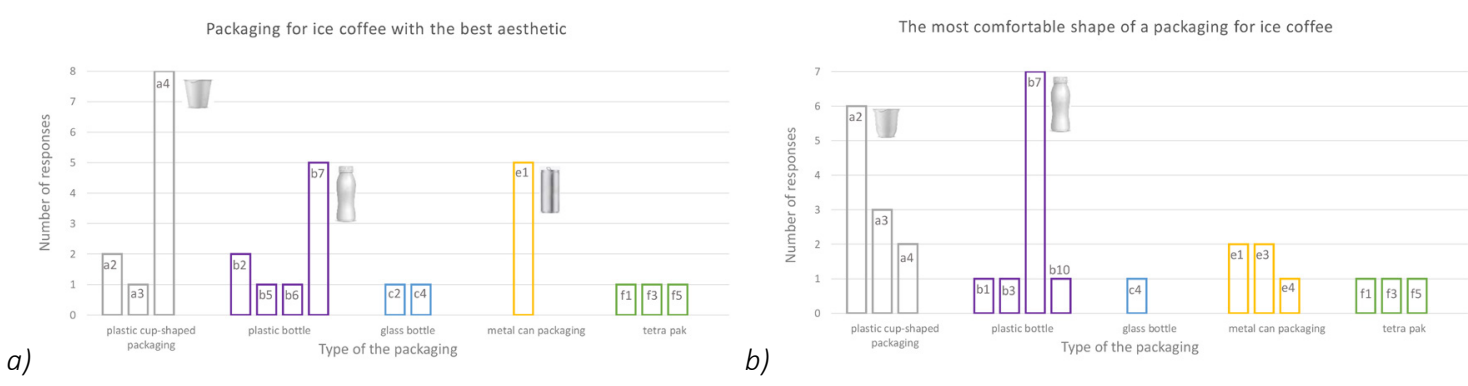

Figure 10: Packaging for ice coffee with the best aesthetic (a) and the most comfortable shape (b) based on participants' ratings

\subsection{Opening and closing system of the packaging}

Since the results of the best opening and closing system of the packaging were almost unanimous, they are presented together for every type of beverage in Figure 11. As it can be seen, for milk (milkshake, chocolate milk) the best opening and closing system had the packaging f6. For yoghurt and fruit yoghurt the packaging that was rated the most was b7, and for water it was b3. For soda drink, participants rated packaging b3 and $\mathrm{e} 2$ as the ones with the best opening and closing system, and for juice, it was b3 and $\mathrm{d} 4$. When it comes to ice coffee, based on participants' rating packaging b7 and a2 were mostly chosen as the best in this category.

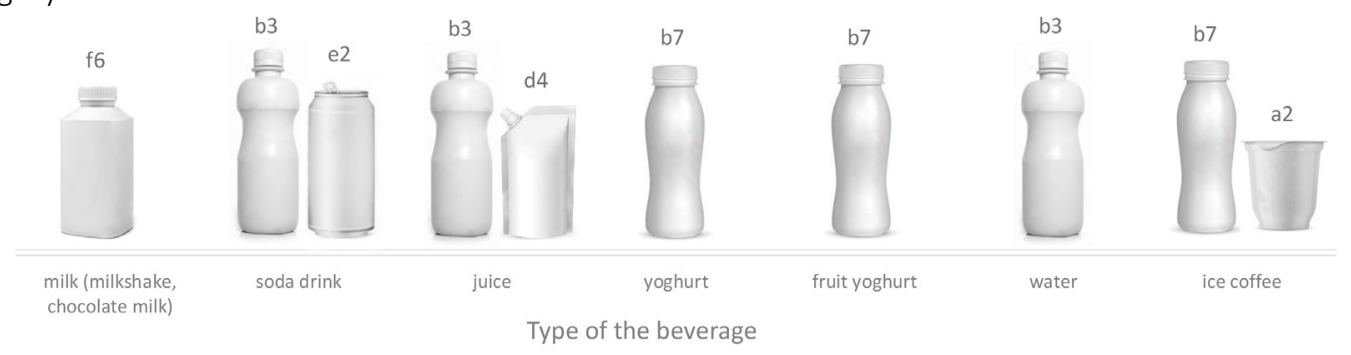

Figure 11: Packaging with the best opening and closing system based on participants' rating

Between types of beverages, a diversity in answers was found. For milk (milkshake, chocolate milk) participants preferred plastic bottles and tetra pak packaging. For soda drink participants preferred plastic bottles and metal can packaging. As packaging for juice, participants preferred plastic bottles and bagshaped packaging. For yoghurt and fruit yoghurt participants preferred plastic bottles. For water, participants preferred plastic bottles and glass bottles, and finally, for ice coffee they preferred plastic bottles and plastic cup-shaped packaging. However, it can be easily noticed that plastic bottles take a large share as a preferred packaging, regardless of the type of the beverage. Even though the plastic bottle is appropriate to every type of a beverage, its shape varies from one beverage to another. For milk, yoghurt, ice coffee and other delicate and subtle flavours, packaging with rounded and curvy shapes were a more common choice, while for soda drink and other sour and sharp flavours complex packaging with angular shapes were a more common choice. The complex packaging was also a common choice for water. When choosing a packaging with the most comfortable shape, participants were focused mostly on the body of the packaging. Often the packaging that was rated as one with the best aesthetic features was also a packaging rated as the one with the most comfortable shape. This means that packaging with good aesthetic values was perceived as a comfortable one, or vice versa, packaging with comfortable shape was perceived as eye pleasing. Since the investigated packaging were evaluated as products that are used outside of the home, results showed that portability, convenience in carrying, opening and closing system were crucial factors in selecting a packaging. For packaging with the best opening and closing system, those with screw thread caps were a clear choice for most types of beverages. When observing the responses of participants separately it is noticed that participants that consumed a certain type of beverage on regular basis were more open for new different atypical packaging shapes. On the other hand, for products that they consumed less, they preferred a packaging that was most commonly presented and placed on the market where they live. 


\section{CONCLUSIONS}

Based on the results of the survey, it can be concluded that the type of a beverage is an influencing factor to its packaging shape. Results collected by a survey indicate that there was a difference in choice of the most suitable packaging between each beverage type. The most common packaging choice, regardless to beverage type, was a plastic bottle. Even though the plastic bottle was defined as appropriate to every type of a beverage, its chosen shape varied from one beverage to another. Packaging with rounded and curvy shapes was a more common choice for beverages with delicate and subtle flavours, while complex packaging with angular shapes was a more common choice for sour and intense flavours and water. Often the packaging that was rated as one with the best aesthetic features was also a packaging rated as the one with the most comfortable shape. This means that packaging with good aesthetic values was perceived as a comfortable one, or vice versa, packaging with comfortable shape was perceived as eye pleasing. Since the investigated packaging were evaluated as products that are used outside of the home, at college or work, as expected, results showed that portability, convenience in carrying, opening and closing system were crucial factors in selecting a packaging. When observing the responses of participants separately, it was noticed that participants that consumed a certain type of beverage on a regular basis were more open for new, different atypical packaging shapes. On the other hand, for products that they consumed less, they preferred a packaging that was most commonly presented and placed on the market where they live. These findings are relevant to those researchers interested in taste-vision correspondences, it should contribute to product communication, and it can be used as a base for future research focused on packaging shape and ergonomics.

\section{ACKNOWLEDGENTS}

The research is supported by the Ministry of Education, Science and Technology Development of the Republic of Serbia, project number: 35027 "Development of software model for scientific and production improvement in graphic industry".

\section{REFERENCES}

[1] Bonfim, F. H.C., Paschoarelli, L.C.: "Visualization and Comprehension of Opening Instructions in Child Resistant Packaging", Procedia Manufacturing 3, 6153-6160, 2015. doi:10.1016/j.promfg.2015.07.906.

[2] Becker, L., Rompay, T.J.L., Schifferstein, H. N. J., Galetzka, M.: “Tough package, strong taste: The influence of packaging design on taste impressions and product evaluations", Food Quality and Preference 22, 17-23, 2011. doi:10.1016/j.foodqual.2010.06.007.

[3] Doorn, G., Woods, A., Levitan, C.A. Wan, X., Valesco, C., Bernal- Torres, C., Spence, C.: "Does the shape of a cup influence coffee taste expectations? A crosscultural, online study", Food Quality and Preference 96, 201-211, 2017. doi:10.1016/j.foodqual.2016.10.013.

[4] Husić- Mehmedović, M., Omeragić, I., Batagelj, Z., Kolar, T.: "Seeing is not necessarily liking: Advancing research on package design with eye-tracking", Journal of Business Research, 80, 145-154, 2017. doi:10.1016/j.jbusres.2017.04.019.

[5] Machiels, C.J.A., Karnal, N.: "See how tasty it is? Effects of symbolic cues on product evaluation and taste", Food Quality and Preference, 52, 196-202, 2016. doi:10.1016/j.foodqual.2016.04.014.

[6] Mai, R., Symmank, C., Seeberg-Elverfeldt, B.: "Light and Pale Colors in Food Packaging: When Does This Package Cue Signal Superior Healthiness or Inferior Tastiness?”, Journal of Retailing, 94 (4), 426-444, 2016. doi:10.1016/j.jretai.2016.08.002.

[7] Mead, J. A., Richerson, R. "Package color saturation and food healthfulness perceptions", Journal of Business Research, 82, 10-18, 2018. doi:10.1016/j.jbusres.2017.08.015.

[8] Ooijen, I., Fransen, M. L., Verlegh, P. W.J., Smit, E. G.: "Atypical food packaging affects the persuasive impact of product claims", Food Quality and Preference, 48, 33-40, 2016. doi:10.1016/j.foodqual.2015.08.002.

[9] Ramos, M., Valdés, A., Mellinas, A. C., Garrigós, M. C.: “New Trends in Beverage Packaging Systems: A Review", Beverages, 1(4), 248-272, 2015. doi:10.3390/beverages1040248. 
[10] Simmonds, G., Woods, A. T., Spence, C.: "'Show me the goods': Assessing the effectiveness of transparent packaging vs. product imagery on product evaluation", Food Quality and Preference, 63, 18-27, 2018. doi: 10.1016/j.foodqual.2017.07.015.

[11] Steenis, N. D., Herpen, E., Lans, I. A., Ligthart, T. N., Trijp,, H. C. M.: “Consumer response to packaging design: The role of packaging materials and graphics in sustainability perceptions and product evaluations", Journal of Cleaner Production, 162, 286-298, 2017. doi: 10.1016/j.jclepro.2017.06.036.

[12] Valesco, C., Salgado-Montejo, A., Marmolejo-Ramos, F. Spence, C..: "Predictive packaging design: Tasting shapes, typefaces, names, and sounds", Food Quality and Preference, 34, 88-95, 2014. doi: 10.1016/j.foodqual.2013.12.005.

[13] Velasco, C., Woods, A. T., Petit, O., Cheok, A. D., Spence, C.: "Crossmodal correspondences between taste and shape, and their implications for product packaging: A review", Food Quality and Preference, 52, 17-26, 2016. doi: 10.1016/j.foodqual.2016.03.005.

[14] Vladić, G., Kecman, M., Kašiković, N., Pal, M., Stančić, M.: "Influence of the shape on the consumers perception of the packaging attributes", Journal of Graphic Engineering and Design, 6 (2), 27-32, 2015. UDC: 655.3.066.25:159.937.522.

[15] Westerman, S.J., Sutherland, E.J., Gardner, P.H., Baig, N., Critchley, C., Hickey, C., Mehigan, S., Solway, A.: "The design of consumer packaging: Effects of manipulations of shape, orientation, and alignment of graphical forms on consumers' assessments", Food Quality and Preference, 27, 8-17, 2013. doi: 10.1016/j.foodqual.2012.05.007.

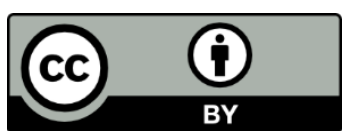

(C) 2018 Authors. Published by the University of Novi Sad, Faculty of Technical Sciences, Department of Graphic Engineering and Design. This article is an open access article distributed under the terms and conditions of the Creative Commons Attribution license 3.0 Serbia (http://creativecommons.org/licenses/by/3.0/rs/). 